\title{
OPTICAL AID FOR PLACING COMPOSITE MATERIAL (PREPREGS) IN A MOULD
}

\author{
J. van der Westhuizen ${ }^{1 \#} \&$ K. Schreve ${ }^{2 *}$
}

\section{ARTICLE INFO}

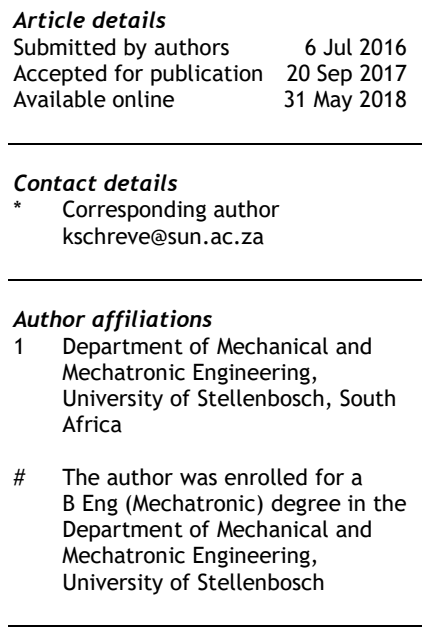

DOI

http://dx.doi.org/10.7166/29-1-1612

\section{ABSTRACT}

Increased industrial use of composite materials for manufacturing strong lightweight components stimulates endeavours for more efficient assembly methods. This study attempted to find an optimal method to provide optical aid for the placement of preimpregnated reinforcing fabric (prepregs). A novel approach to optical assistance for the placement of prepregs was designed to be straightforward and affordable. The developed system meets industry standards for accuracy, and provides the solution at a cost many times less than existing solutions. The findings allow companies in the composite material industry to eliminate prepreg layup errors at an affordable price.

\section{OPSOMMING}

'n Toename in die gebruik van saamgestelde materiale vir vervaardiging van sterk, liggewig komponente stimuleer pogings vir meer effektiewe samestellingsmetodes. Die doel van hierdie studie was om 'n optimale metode te vind vir die optiese ondersteuning in die plasing van vooraf geïmpregneerde materiaal. 'n Nuwe benadering vir optiese ondersteuning vir die plasing van vooraf geïmpregneerde materiaal is ontwerp om bekostigbaar en eenvoudig te wees. Die ontwikkelde benadering voldoen aan die industrie se standaarde vir akkuraatheid, en bied die oplossing teen 'n prys wat aansienlik minder is as bestaande oplossings. Die bevindinge bied besighede in die saamgestelde materiaal industrie met ' $n$ bekostigbare oplossing om vooraf impregnering plasing foute te elimineer.

\section{INTRODUCTION}

Composite material is increasingly becoming a design choice in current technological advances to manufacture strong and lightweight components. One of the predominant techniques of manufacturing composite material projects requires the use of pre-impregnated reinforcing fabric ('prepregs'). Pre-cut pieces of composite material that are assembled to form a composite part are called 'prepregs' (also known as 'plies'). This material is typically pre-infused with a resin. After assembly, the component is typically cured in an autoclave to ensure proper bonding. This process allows a high level of control of the fibre direction, thereby ensuring an optimal structural design. Aircraft seats and performance-car body parts are examples of composite material applications. Companies in this industry lose a substantial amount of money due to faulty composite parts [1]. One of the main causes for these faults is the fact that the prepregs are not always placed correctly, which is only realised after curing.

In a completely manual layup process, a printed document, referred to as a work instruction set, is used. This document has the images and the identification number of each prepreg to indicate where it must be placed. The work instruction set is the only guide that the technician receives, and it is up to him/her to make sure that there are no mistakes in the layup of the prepregs. This clearly causes the process to be time-consuming and susceptible to human error. The performance of the 
task relies on the technician's experience and familiarity with each part. Faults are only detected after curing, resulting in the complete loss of the component.

Current layups begin with the technician placing the mould on the working surface of the layup station. Prior to placement, the prepregs are covered with coloured plastic protective sheets. The technician removes the sheet on one side and places the prepreg in the location indicated in the work construction set, with the remaining sheet preventing contamination. After the prepreg has been properly fitted and manually pressed into place, the remaining sheet is removed, allowing the next prepreg to adhere to the current one. A common undesirable occurrence is 'bridging', which arises when prepregs are not properly fitted into corners, as shown in Figure 1.
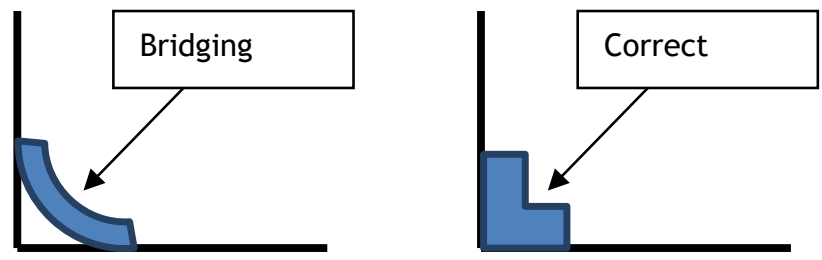

Figure 1: Example of bridging, as seen in a cross section through one prepreg and the mould

The aim of the study is to design an optical aid system to improve the efficiency of the prepreg layup process. The proposed system will project an image on to the working surface, indicating where the prepregs must be laid; thereafter the placement of the prepreg will be inspected with a camera.

\section{EXISTING SOLUTIONS}

\subsection{PlyMatch}

This is a solution designed by Anaglyph Ltd to aid the manual layup of small composite parts. The solution is based on augmented reality, with a set of equipment that allows the projection of the prepreg on to a screen that carries a live video feed of the mould [2]. The system consists of a digital camera, a sensor, two probes, a monitor, a coordinate-measuring machine incorporated into a computer, and a wireless calibration probe. One probe is attached to the mould and the other to the camera. The wireless calibration probe is required to locate the mould in space.

The software drives the augmented reality and projects the outline of the prepreg to be laid on to the real-time picture of the mould being displayed on the monitor. PlyMatch is a portable system that can be disassembled and assembled quickly and easily. Placement was designed to work seamlessly with any computer-aided design (CAD) or laminate tools data. The quoted accuracy of the system is $+/-1 \mathrm{~mm}$, and the cost of the main system, including installation and training, is GBE26, 900 (price valid in October 2014).

\subsection{Laser projection systems}

Assembly Guidance, LAP Laser, Virtek Vision International Inc., and Laser Projection Technologies (LPT) are some of the companies that produce state-of-the-art technology in laser projection systems for composite applications. The basic laser projection system consists of a projector mounted above the layup area, a set of retro-reflective alignment pins, and a computer controller. The alignment pins are positioned on the tool edges and are used as reference points to establish the tool's exact position in three-dimensional space.

The system software stores imported CAD outlines of prepregs, and adjusts the size and shape of the projected outline to account for the tool's three-dimensional contours. The system can then accurately project the outline of each prepreg to be laid; the technician simply pushes a button to advance to the next pattern. At the heart of the projector is a laser that, accompanied by a set of mirrors and galvanometers, travels the path of the prepreg outline at a speed great enough to appear as a solid line. 
All four companies mentioned above have reported accuracies within $\pm 0.38 \mathrm{~mm}$. Depending on the manufacturer, the prices for these systems range from US\$85,000 to US\$100,000 (October 2014). Users of these systems have reported that they eliminate 80 per cent of the fabrication time [3].

\subsection{Automatic ply verification}

Automatic ply verification (APV) is an in-process quality monitoring system, which is a feature of the assembly guidance systems produced by Vistagy. It is a controller-based feature that electronically inspects some or all of the patterns in a particular layup. After the technician has laid one of the prepregs, and before advancing to the next pattern, the technician is prompted to place a digital camera mounted on a small bracket on the layup. The base of the bracket sits on the surface, while the bracket holds the camera a few centimetres above the prepreg to be inspected.

The controller acquires a digital image of the prepreg wirelessly. The system then automatically uses the image to determine whether or not the fibre orientation, material type, and ply position are correct. The controller stores the result, which can then be sent with the part to the client. The APV system prevents the technician from proceeding to the next layup pattern until the inspection results fall within the manufacturing tolerances [4].

\subsection{Projector vision system}

Laserguide ProjectorVision is a system produced by Vistagy. This system works in conjunction with the APV system. If a problem is detected, ProjectorVision immediately stops the process so that the error can be corrected at the lowest possible cost. The Laserguide projection function displays a pattern at the location where the problem has been detected [4].

This system also has the ability to scan 3D objects to gather coordinate information in the form of a 'point cloud' using reflective data from each point scanned on the object. The projectors then display a high-speed glowing image directly on to the surface where the discrepancies are located [5]. The system has an accuracy of $0.38 \mathrm{~mm}$ [6].

\subsection{Video projection systems}

Twin Coast is a company that uses standard video projectors to create visual guidance and monitoring systems for the laying of prepregs. The projectors used are supplied by leading manufacturers such as Sony, Casio, and Infocus, which results in lower costs and improved performance efficiency. The video projectors also provide other benefits over laser projectors, such as the elimination of incessant blink, eye safety, and dimming [7]. This system can only be used to guide the placement of prepregs, whereas the optical aid system designed as part of this project also inspects the placement. The system has an accuracy of $2 \mathrm{~mm}$ when used for applications similar to those explored in this study.

\section{FUNCTIONAL SYSTEM DESCRIPTION}

The optical aid system was designed to aid the technicians in placing the prepregs for the assembly of a part. The program starts by displaying a 'start screen', where user input triggers an image to be displayed by the projector on to the working surface. The first image displayed by the projector is the scaled top view of the mould. The mould must then be placed in the area indicated by the image. User input then triggers an inspection by the camera, when the placement is either passed or rejected.

Before the placement of the mould is inspected, it is fastened with clamps to ensure that it does not move relative to the camera and projector. The fastening of the mould acts as a fixed reference for the system; this ensures that the camera and projector are at the correct position relative to the mould throughout the layup process. While the images are displayed by the projector, the work instruction set is displayed on the computer screen to guide the technician further.

If the placement is rejected, the same image is displayed by the projector, after which the inspection must be triggered again. The process of displaying and inspecting continues for all of the prepregs that must be placed. At the end of the layup, the time it took to complete the assembly is displayed and saved; this can be used by the company to determine how long certain parts take to 
make and how the technicians perform. The flow diagram in Figure 2 illustrates the flow of the functional system.

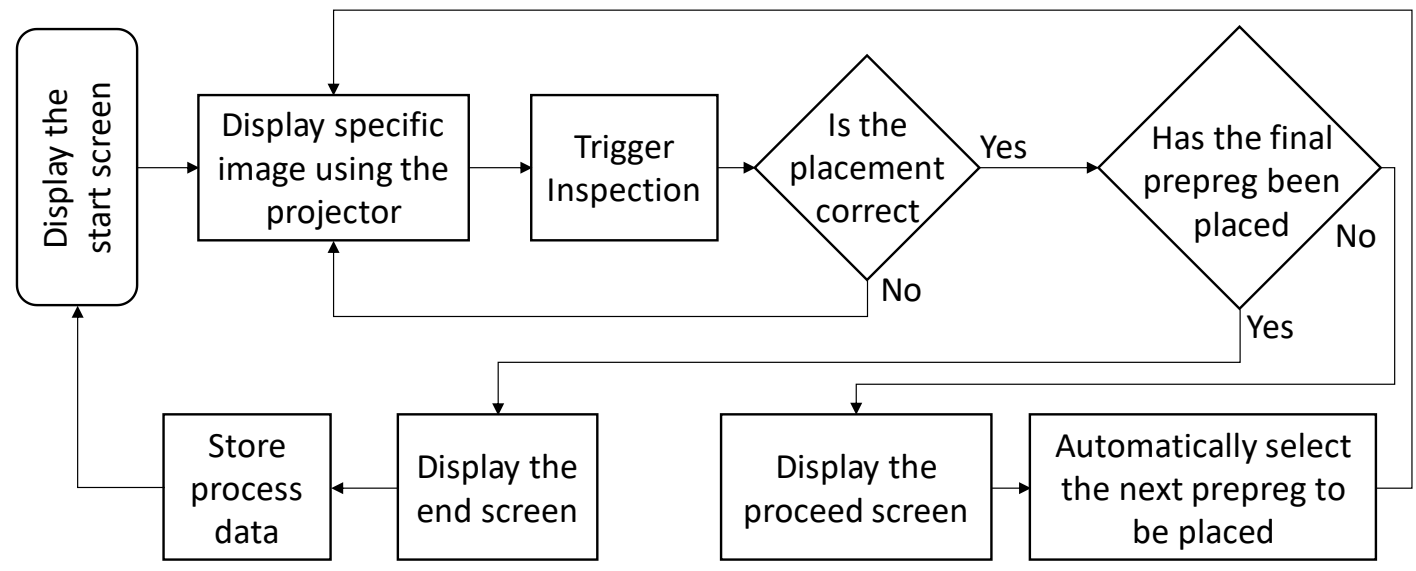

Figure 2: Functional system flow diagram

\section{HARDWARE}

The hardware used for the optical aid system consists of four main components: a computer, a projector, a camera, and a mechanical stand. Figure 3 illustrates the physical setup of the proof of concept for the optical aid system.

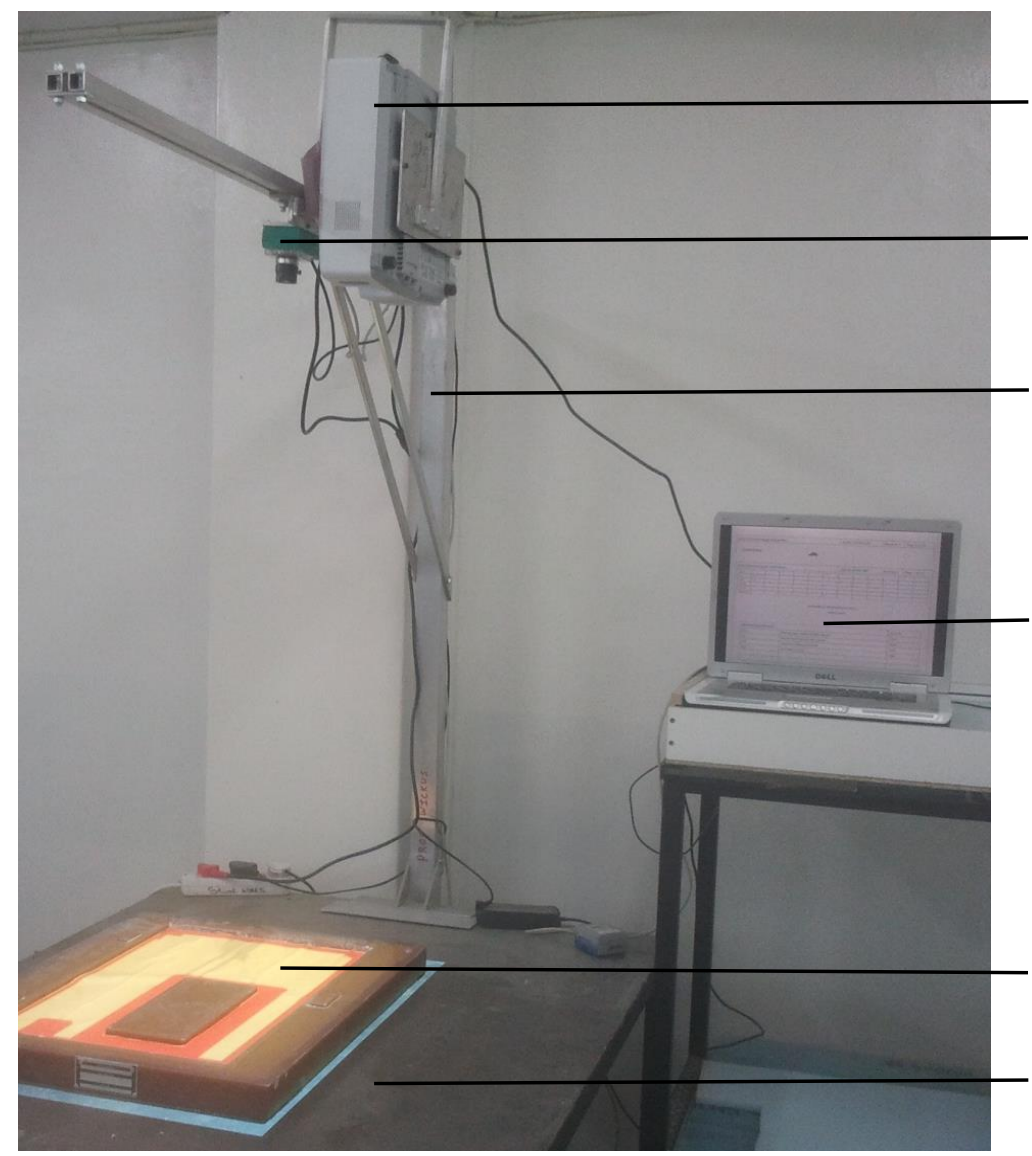

Projector

Camera

Mechanical stand

Computer

Mould prepreg and projected image

Workbench

Figure 3: Optical aid system setup (see online version for colour) 


\subsection{Projector}

The requirements for the projector to function properly in the designed system are listed below:

- It must be able to display an image with a size of $1.6 \mathrm{~m} \times 1.2 \mathrm{~m}$ on to the working surface, with the lens being $1.1 \mathrm{~m}$ from the working surface. (This is an application-specific requirement.)

- The centre of the projected image must be in line with the centre of the projector lens.

- The resolution must be equal to, or higher than, $1600 \times 1200$ to ensure that one pixel of the projector does not exceed a size of $1.1 \mathrm{~mm}$ on the working surface. (The resolution was determined in consultation with the company where the testing was done.)

The throw ratio of a projector is the relationship between the distance from the projector lens to the screen, and the width of the image displayed. Equation 1 shows the relationship.

Throw ratio $=\frac{\text { Distance }}{\text { Image width }}$

Thus, from the first requirement, it was derived that the throw ratio should be smaller than or equal to 0.6875 .

The offset of a projector measures the position of the image relative to the centreline of the lens of the projector. An offset of 0 per cent means that the centre of the image projected aligns with the centreline of the lens. Thus the required offset of the projector is 0 per cent. This allows for the mechanical stand to be placed in the middle of the working surface.

The projector that was readily available for the proof-of-concept was a Hitachi ED-X42 3LCD model. This projector has a brightness ranging from 1500 to 2200 ANSI lumens, depending on the set mode. It was empirically determined that approximately 2200 ANSI lumens provided a satisfactory display and fault-detection performance. The projector has a throw ratio ranging from 1.49 to 1.76 , with a zoom ratio of 1.2. The throw ratio of this projector is too large, and thus the image displayed on the working surface is too small. The projector displays a $0.738 \mathrm{~m} \times 0.554 \mathrm{~m}$ image from the design distance of $1.1 \mathrm{~m}$, calculated with Equation 1 and the minimum throw ratio. To test the proof-ofconcept fully with the smaller projected image, a part smaller than the projected image was used.

\subsection{Camera}

The camera used to monitor the placement of the prepregs was a DVT Legend 540 camera supplied by Cognex. The camera was placed next to the projector, also pointing downwards to monitor the working surface from above. The properties of the camera are tabulated in Table 1. This is a smart camera, with onboard image processing and programming capabilities (using Intellect software).

Table 1: Legend 540 camera properties

\begin{tabular}{llll}
\hline Description & Resolution & CCD format (size) & Lens mount (optional) \\
\hline High speed gray scale CCD & $640 \times 480$ & $4.8 \times 3.6 \mathrm{~mm} \mathrm{(1/3")}$ & $\begin{array}{l}\text { CS mount (C mount with } \\
\text { adapter) }\end{array}$ \\
\hline
\end{tabular}

Figure 4 illustrates the aspects for calculating the required field of view (FOV). The distance from the lens to the working surface is $1120 \mathrm{~mm}$. The horizontal image size required to be able to view the whole working surface is $1600 \mathrm{~mm}$. The relationship between the FOV angle $(2 \alpha)$ and the viewing distance is depicted in Equation 2.

$x=2 h \tan \alpha$

Equation 2 produces an $\alpha$ of $35.54^{\circ}$, which means that the lens should provide a FOV angle of $71.08^{\circ}$. The required focal length of the lens used was calculated to be smaller than, or equal to, $3.59 \mathrm{~mm}$. The SL183M lens from Theia was used in this project. This lens has a focal length that ranges between $1.8 \mathrm{~mm}$ and $3 \mathrm{~mm}$. The $3 \mathrm{~mm}$ focal length of the Theia lens resulted in a FOV of $1971 \mathrm{~mm} \times 1478 \mathrm{~mm}$ for the current setup. Together with the $640 \times 480$ resolution of the sensor, the lens results in one pixel representing $3.08 \mathrm{~mm}$. To achieve the required spatial resolution, a higher resolution camera must be used, but this was not available for the proof-of-concept. 


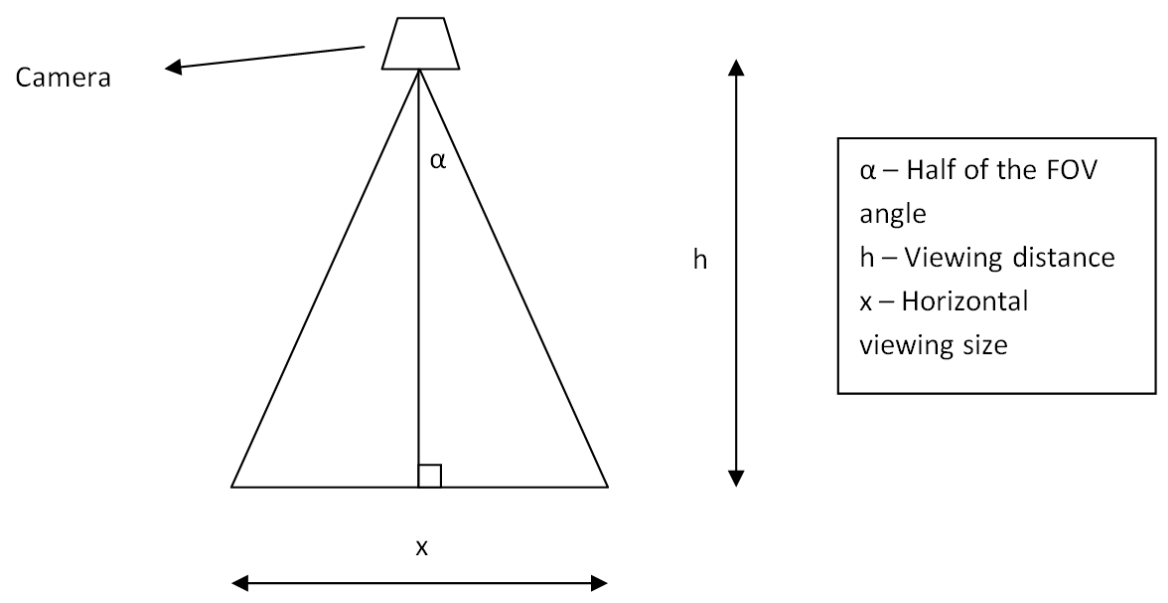

Figure 4: Camera FOV calculation

Consequently, two other lenses were used to test the effect of spatial resolution.

An $8 \mathrm{~mm}$ Cinegon compact lens supplied by Schneider was readily available for testing. It has a focal length of $8 \mathrm{~mm}$, producing a horizontal viewing size of $716 \mathrm{~mm}$, which resulted in one pixel representing $1.12 \mathrm{~mm}$, which was much closer to the required spatial resolution. The FOV of the lens has the largest impact on the accuracy of the system.

A Tamron 23FM16SP lens was used to test the effect of a longer focal length on the accuracy. This lens has a focal length of $16 \mathrm{~mm}$, resulting in a FOV of $333 \mathrm{~mm} \times 250 \mathrm{~mm}$. The small FOV results in one pixel representing $0.521 \mathrm{~mm}$. This was much more accurate than the Schneider lens. Table 2 gives the details of the three lenses used.

Table 2: Specification comparison of lenses used in the tests

\begin{tabular}{lccc}
\hline Lens & Theia SL183M & Schneider $8 \mathrm{~mm}$ Cinegon compact & Tamron 23FM16SP \\
\hline Resolution [mm/pixel] & 3.08 & 1.12 & 0.521 \\
FOV $[\mathrm{mm}]$ & $1971 \times 1478$ & $716 \times 537$ & $333 \times 250$
\end{tabular}

\section{SOFTWARE}

Two programs were created, one in Java and the other in DVT Intellect 1.5.1, and socket programming was used for virtual communication between the parallel running programs.

\subsection{DVT Intellect}

DVT Intellect 1.5.1 enables the end-user to inspect the images. Special tools allow flaw detection by learning the required pixel pattern in a predefined region of interest, which is then compared with the actual image. The software counts the number of errors in the region of interest and, based on a predefined threshold, gives a pass or fail result.

\subsection{Projected images}

The images that are projected on to the working surface are created by the user. The process starts in any CAD software. A perspective two-dimensional top view of the entire part with all its layers should be made in CAD. A $0.738 \mathrm{~m} \times 0.554 \mathrm{~m}$ image is projected on to the mould. This gives a spatial resolution of $0.461 \mathrm{~mm}$. Figure 5 shows an example of the prepreg placement guidance. The projected green area shows where the prepreg should be placed on the brown mould. 


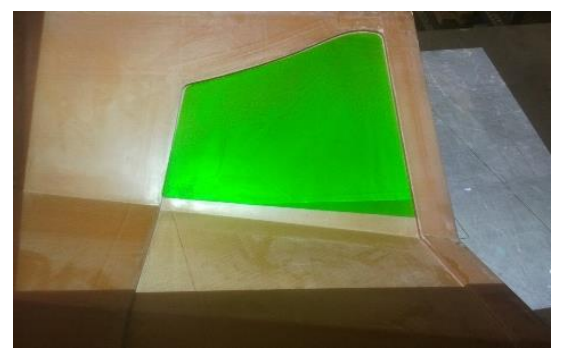

Figure 5: Image projection example (see online version for colour)

\section{IMAGING THEORY}

\subsection{Anti-blooming}

Blooming occurs when the charge in a pixel exceeds the saturation level and the charge starts to fill adjacent pixels. With typical CCD sensors, the excess charge will preferably flow into the nearest vertical neighbours. Blooming, therefore, produces a characteristic vertical streak. Anti-blooming structures bleed off any excess charge before they can overflow the pixel, thus stopping the blooming [8]. For the optical aid system, anti-blooming caused the contrast between the prepregs to be too small, and thus the physical light system had to be set up to reduce the blooming.

\subsection{Defect size}

The defect detection vision tool in Intellect allows for the adjustment of the size of the defects to be detected. An exact definition of the defect size remains unknown, due to inadequate documentation by the software supplier. A smaller defect size results in smaller defects being detected, and thus allows for a more accurate inspection. The number of defects before the inspection is failed can also be specified, providing the user with the ability to make the inspection less accurate and more robust when accuracy of the placement is not critical.

\section{SYSTEM TESTING AND EVALUATION}

\subsection{Standard test setup}

Figure 6(a) illustrates the standard test setup used to determine the translation accuracy of the optical inspection system. (The required value of the translation accuracy was not known to the authors; an estimate of better than $5 \mathrm{~mm}$ was aimed for.) The prepreg was placed parallel to the image plane, on a flat table, and its placement was marked. It was then moved in the indicated directions. As soon as the inspection failed, the distance that the prepreg was displaced was measured with a digital vernier. Each of the four directions of translation was tested three times, and the results compared were the averages of the 12 measurements. Figure $6(\mathrm{~b})$ illustrates the shape and size of the prepreg used in all of the test setups.

The translation accuracy is therefore a threshold for a successful inspection. For a high value, the prepreg can be misplaced significantly before the error is detected.

The Schneider lens was used as the default lens. The Intellect software package allows for the defect size to be altered, depending on the accuracy required. The default setting of a 100 defect size was used for all the testing. This allowed for more accurate measurements and analysis, as a smaller defect size parameter would mean smaller displacements.

\subsection{Statistical design of experiments and analysis of variance}

The setup of the optical aid system has several factors that influenced the performance. Here, a 'design of experiments' [9] approach was used to determine the sensitivity of the system accuracy to the variation of the system parameters. 


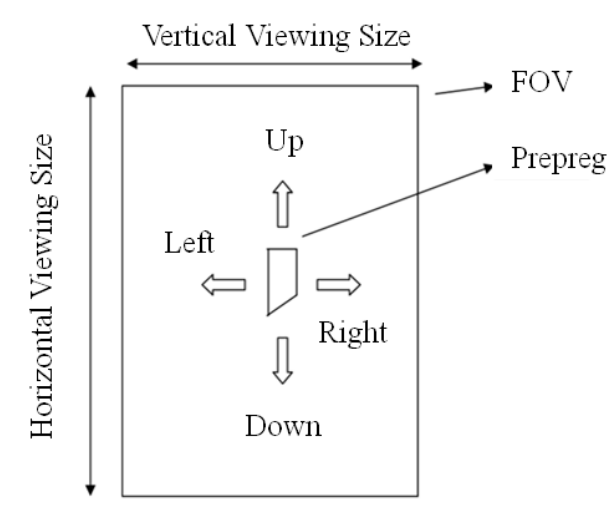

(a) Schematic
$54.9 \mathrm{~mm}$

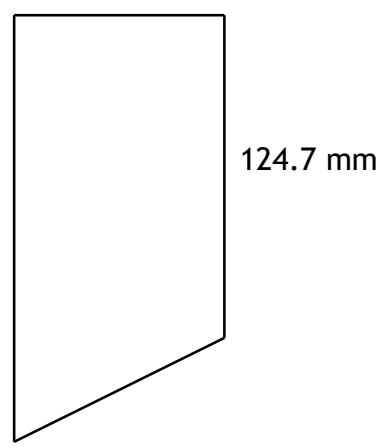

(b) Prepreg

Figure 6: Standard Ttest

A two-level fractional factorial experiment was conducted. The high and low values are denoted by + and - in Table 4. These experiments can be time-consuming, since the number of factors to be tested is $f$, the number of levels is $L$, and the number of replications is $r$; the number of tests to be performed is then $r L^{f}$. To simplify the experiment further, some test combinations were eliminated. Table 3 gives the system parameters and their high and low settings.

Table 3: Components of factorial experiment

\begin{tabular}{llll}
\hline \multirow{2}{*}{ Component } & Description & + & - \\
& & & \\
\hline A & Camera exposure (ms) & 25 & 10 \\
B & Aperture setting (f-stop) & 11 & 5.6 \\
C & Broken light/obstruction* & Yes & No \\
D & Anti-blooming & On & Off \\
E & Multiple detectors & Yes & No \\
F & Illumination & Yes & No \\
G & Automatic gain adjustment & Yes & No
\end{tabular}

*Impact of surrounding light was tested by simulating a broken light or an obstruction.

The design of experiments process [9] recommends that the number of experiments can be reduced by assuming that the interaction of certain parameters is insignificant. The number of tests was reduced by eliminating higher level interaction of the parameters. The experiment was designed on the basis that parameters $\mathrm{D}, \mathrm{E}, \mathrm{F}$, and $\mathrm{G}$ were considered less significant than the aliased interactions. (Two parameters or effects are aliased when their test sequences are the same. In Table 4, parameter $D$ has the same pattern of + and - as the interaction of the parameters $A$ and $B$; therefore the effect of $D$ and $A B$ cannot be separated numerically.) The results found in the tests for parameters D, E, F, and G are, therefore, a combination of their main effects and the two-factor interaction of the aliased parameters.

Table 4 tabulates the results obtained for the fractional factorial experiment. The alias row indicates which combinations were considered to be the main effects. The response value shown in the table is the average accuracy result, calculated from performing the standard test setup with the factors set as indicated.

Table 5 tabulates the main effects, which were simply calculated by averaging the difference between the response values for each high and low factor setting. The calculation for component A is shown below:

$[(3.9-5)+(3-5.5)+(3.9-4.9)+(3.1-4.1)] / 4$ 
Table 4: Sixteenth fractional factorial layout for seven main effects

\begin{tabular}{lllllllll}
\hline Test no. & A & B & C & D & E & F & G & Accuracy $(\mathrm{mm})$ \\
\hline 1 & + & + & + & + & + & + & + & 3.9 \\
2 & + & + & - & + & - & - & - & 3 \\
3 & + & - & + & - & + & - & - & 3.9 \\
4 & + & - & - & - & - & + & + & 3.1 \\
5 & - & + & + & - & - & + & - & 5 \\
6 & - & + & - & - & + & - & + & 5.5 \\
7 & - & - & + & + & - & - & + & 4.9 \\
8 & - & - & - & + & + & + & - & 4.1 \\
\hline Alias & & & & AB & AC & AD & ABC & \\
\hline
\end{tabular}

Table 5: Main effects (displacement before failure $[\mathrm{mm}]$ )

\begin{tabular}{llllllll}
\hline Component & A & B & C & D & E & F & G \\
\hline Effect & -5.6 & 1.4 & 2 & -1.6 & 1.4 & -1.2 & 1.4 \\
\hline
\end{tabular}

Table 6: Sum of squares

\begin{tabular}{lr}
\hline Component & \multicolumn{1}{c}{ Ss } \\
\hline Exposure & 1003.52 \\
Aperture & 62.72 \\
Broken light/obstruction & 128 \\
Anti-blooming & 81.92 \\
Multiple detectors & 62.72 \\
Illumination & 46.08 \\
Automatic gain adjustment & 62.72 \\
\hline
\end{tabular}

From Table 6 it can be seen that the variance of the exposure is the most critical factor in the setup of the system for obtaining the best results. Another factor requiring control is the surrounding light (broken light/obstruction), which forms the second most important factor for obtaining the best results. The sum of squares indicates the significance of each component as obtained from the experiment. The sum of squares (SS) is calculated using Equation 3.

SS $=\left(2^{k-2}\right)(\text { effect estimate })^{2}$

where $k$ is the number of components.

Table 6 shows the sum of squares of the components.

\subsection{Translation accuracy}

In order to ensure that the results obtained for the analysis of variance are correct, further evaluation was done to investigate specific aspects. The default settings for all the test setups are tabulated in Table 7. Table 8 provides the average displacement measured for each of the tests conducted. With each test, the description indicates which settings were altered from the default settings. The results of the performed tests established the most favourable settings. Setups 1 and 2 indicate that anti-blooming causes the inspection system to lose accuracy. Test setups 3 and 4 indicate that both reducing the amount of light entering the lens and increasing exposure time too much decreases the resulting accuracies. Test setup 6 produced the most accurate results, and so these settings would be used for the final system setup. In this setup, the aperture was set to f8 to nullify the undesirable effects of the bright projector light.

Test setup 7 proved that multiple defect detection vision tools decreased accuracy. As expected, accuracy decreased towards the edges of the FOV, as proved in test setup 8. It was found that an analysis of larger prepregs could be performed more accurately. Moreover, the findings prove that tolerances of less than $1 \mathrm{~mm}$ could be achieved. This is a result of the significant effect of the defect detection size and the FOV of the lens used, where a larger FOV produces a lower accuracy. 
Table 7: Default test setup settings

\begin{tabular}{ll}
\hline Component & Setting \\
\hline Aperture & f5.6 \\
Exposure & $20 \mathrm{~ms}$ \\
Anti-blooming & Off \\
Illumination & Off \\
Projector illumination & Off \\
Defect size & 100 \\
\hline
\end{tabular}

Table 8: Summary of the results of each test

\begin{tabular}{lll}
\hline $\begin{array}{l}\text { Test } \\
\text { setup }\end{array}$ & Description & $\begin{array}{l}\text { Average } \\
\text { displacement } \\
\text { [mm] }\end{array}$ \\
\hline 1 & & 3 \\
2 & Anti-blooming on & 2.95 \\
3 & All settings at default & 2.97 \\
4 & Aperture f8 & 3.18 \\
5 & Exposure 15 & 3.45 \\
6 & Illumination on & 2.93 \\
7 & Projector illumination on, aperture f8, exposure 15 & 3.06 \\
8 & All settings at default with multiple defect detection vision tools set up & 3.14 \\
9 & All settings at default with the prepreg placed on the edge of the FOV & 2.50 \\
& All settings at default with the prepreg moved in each diagonal direction & \\
10 & (e.g., up and right) & 1.76 \\
11 & All settings at default with an irregular large shaped prepreg & 3.56 \\
12 & All settings at default with a small prepreg & 3.04 \\
13 & All settings at default with the default prepreg rotated 90 ${ }^{\circ}$ & 0.91 \\
14 & Defect size 1 & 3.29 \\
15 & All settings at default with the prepreg placed on a 45 ${ }^{\circ}$ slope & 2.50 \\
& All settings at default with the standard test done on a flat piece of a & \\
16 & mould & $<0.1$ \\
17 & Defect size 1 with the Tamron lens & 1.45 \\
18 & All settings at default with the Tamron lens & 3.60 \\
19 & All settings at default, and rotation accuracy was evaluated & 2.28 \\
20 & Defect size 25 & 4.23 \\
21 & All settings at default with an obstruction or broken light simulated & 2.17 \\
22 & Defect size 5 with the standard test on another prepreg & 13.78 \\
23 & Defect size 25 with the Theia lens & 3.63 \\
24 & Defect size 5 with the Theia lens & 2.12 \\
\hline
\end{tabular}

\subsection{Bridging}

A solution to bridging was one of the critical concerns for this system. A few tests were performed to find the optimal method for detecting bridging. Figure 7 illustrates the test setup for bridging. The first attempt was an inspection of the complete prepreg. This could not solve the bridging. At a defect size below 10, it was impossible to place the entire prepreg in the correct position. A defect size of at least 2 was necessary to detect bridging.

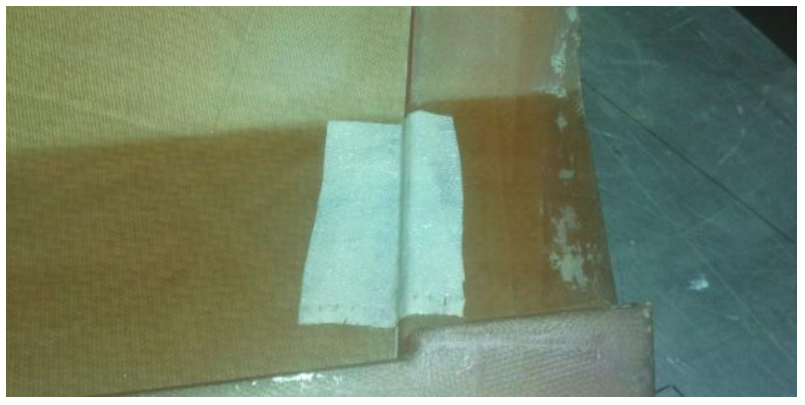

Figure 7: Bridging setup (see online version for colour)

The second attempt was to project shapes on to the area where bridging occurs, and then to detect the shape's distortion. This proved to work at a defect size of 1 . The area of inspection was smaller than with the first method, and thus correct placement was made easier. A triangle, a line, and a 
circle were used as projection shapes. A triangle with thin lines produced the best results. Figure 8(a) illustrates a thick-lined circle projected on to the bridging area for detection. Figure 8(b) illustrates a thick-lined triangle projected on to the bridging area, as seen by the camera.

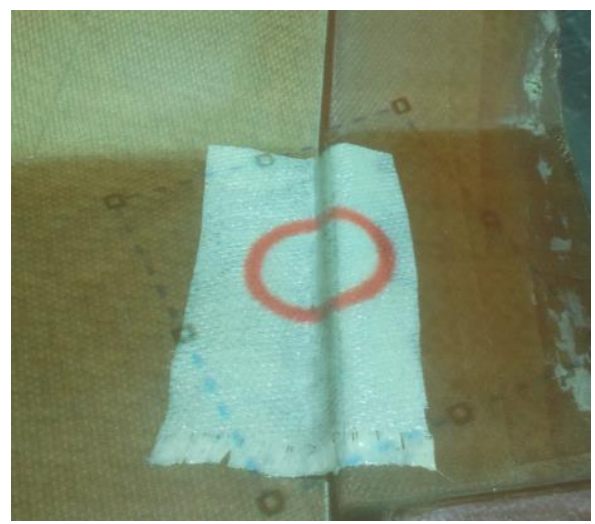

(a) Using a circle

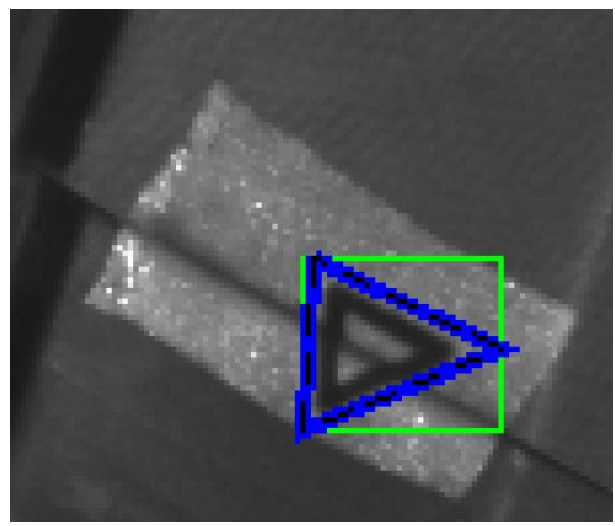

(b) Using a triangle

Figure 8: Testing for bridging (see online version for colour)

The third method was only to inspect the edge of the prepreg that would be misplaced if bridging occurred. This proved to be effective at a defect size of 1 . This method and the second method were compared at the same time to determine which would be most effective. It was found that the area inspected in method 3 was smaller than the area in method 2, and thus it was easier to place the prepreg correctly with method 3 . With method 3 , however, it was crucial that the edge being inspected had to be positioned parallel to the bridging line. Also, the triangle projected did not detect as many errors as the edge detection, due to smaller defects in the projected area. Another problem with method 2 was that the bridging was only detected in the area where the projection was made; it could thus be passed over in that area, but the area next to it could still be subjected to bridging. Consequently, the third method produced the most acceptable way to detect bridging. Figure 9 shows the second and third methods for solving bridging being implemented simultaneously. As seen in the figure, Tool 17, representing the third method, detects more defects when bridging occurs than does Tool 16, representing the second method.

\subsection{Validation of sample sizes}

Given that each direction that was tested in a different setup has different results, the standard deviation was calculated for each sample of three tests. The maximum standard deviation found in all of the samples was $0.15 \mathrm{~mm}$. The average of the standard deviations for the four directions was calculated to indicate how accurate each of the final results was for each test setup. Table 9 tabulates the average standard deviations for the Design of Experiments (DOE) tests. The required sample size, given a certain margin of error, was calculated using Equation 4.

$n \geq\left(z \frac{\sigma}{E}\right)^{2}$

where:

$E$ is the margin of error

$z$ is the $z$-value for a specific level of confidence

$\sigma$ is the standard deviation of the sample

$n$ is the sample size 


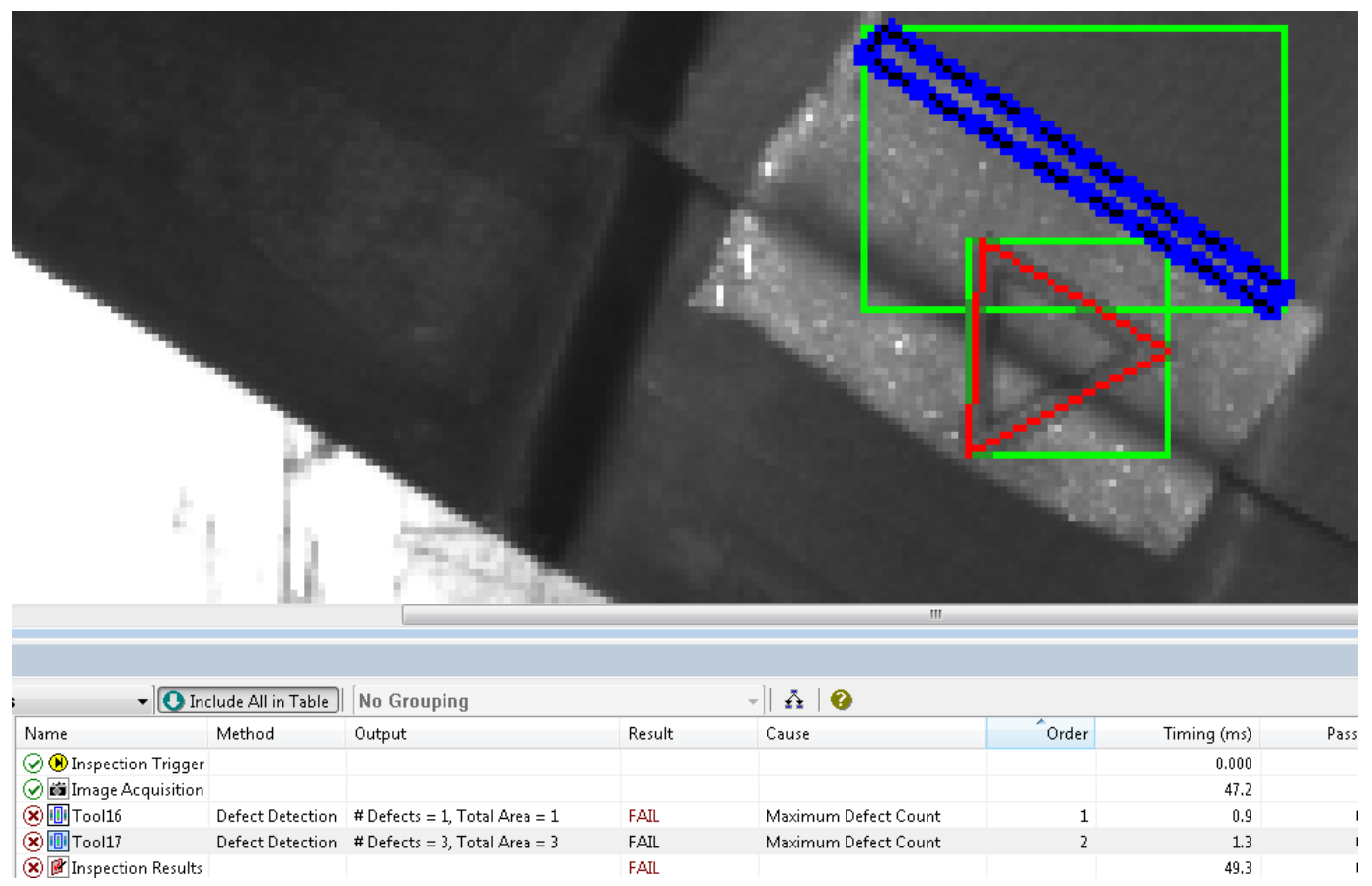

Figure 9: Comparison of bridging tests (see online version for colour)

Table 9: DOE standard deviation of displacement before failure [mm]

\begin{tabular}{lcccccccc}
\hline Test number & 1 & 2 & 3 & 4 & 5 & 6 & 7 & 8 \\
\hline $\begin{array}{l}\text { Average standard } \\
\text { deviation [mm] }\end{array}$ & 0.04 & 0.03 & 0.06 & 0.06 & 0.06 & 0.09 & 0.07 & 0.07 \\
\hline
\end{tabular}

For the testing, the margin of error was set at the industry standard of five per cent. The confidence level was 95 per cent, resulting in a $z$-value of 1.96. The standard deviation was conservatively chosen to be the highest, which is $0.09 \mathrm{~mm}$, from the average standard deviations. With these values, a minimum sample size of 12 was attained. This shows that the 12 measurements resulting in the final average accuracy were based on a large enough sample size. Table 10 tabulates the average standard deviations for the results of the translation accuracy tests.

The standard deviations agree with the conclusions drawn from the average accuracy values of each of the test setups. The test settings in test setup 6 were identified as the most acceptable, and are supported by the results as having the smallest standard deviation. Smaller standard deviations correspond to finer-tuned detection settings. The test setups with larger standard deviations were found to have discrepancies in lighting angle effects on the prepreg. The accuracies of test setups 9 and 16 were measured diagonally and in degrees respectively; consequently, the standard deviations were not applicable for comparison. Furthermore, test setup 9 produced accuracies too small to measure, and thus the standard deviation could not be calculated.

\section{COST ANALYSIS}

This section details the cost of the optical aid system, given the prime components. Table 11 tabulates the cost for each of the optimal components required for the system. The total cost of the system was found to be ZAR37,057.

The costs in Table 11 only give the component cost. Retail costs for the developed system were not estimated, and therefore a direct comparison with the systems described earlier is not possible. However, the system's accuracy can be compared. It is in the same order as some of the commercial systems. Consultation with an industry partner showed that the required prepreg placement tolerance for this kind of work varies between $1.5 \mathrm{~mm}$ and $5 \mathrm{~mm}$, which shows that the developed system can satisfy their requirements. 
Table 10: Accuracy test standard deviation

\begin{tabular}{cccc}
\hline Test setup & Average standard deviation [mm] & Test setup & Average standard deviation [mm] \\
\hline 1 & 0.08 & 13 & 0.04 \\
2 & 0.08 & 14 & 0.08 \\
3 & 0.06 & 15 & 0.07 \\
4 & 0.08 & 16 & N/A \\
5 & 0.07 & 17 & 0.10 \\
6 & 0.04 & 18 & N/A \\
7 & 0.07 & 19 & 0.05 \\
8 & 0.06 & 20 & 0.07 \\
9 & N/A & 21 & 0.04 \\
10 & 0.06 & 22 & 0.09 \\
11 & 0.04 & 23 & 0.06 \\
12 & 0.04 & 24 & 0.04 \\
\hline
\end{tabular}

Table 11: System component costs

\begin{tabular}{llr}
\hline Component & Supplier & Cost [R] \\
\hline SL183M lens & Theia Technologies & 3,294 \\
Machine Vision Legend 540 camera & Cognex & 9,122 \\
DVT Isolated BOB & Cognex & 2,790 \\
ProjectoWrite3 WX25NU & Boxlight & 12,731 \\
Pre-built computer and 18" monitor & Landmark Computers & 6,032 \\
Mechanical stand material & Stalcor & 459 \\
Mechanical stand manufacturing labour & Stellenbosch University Mechanical & 2,629 \\
& Workshop & 37,057 \\
\hline
\end{tabular}

Table 12: Comparison of the proposed system with some commercially available systems

\begin{tabular}{|c|c|c|c|c|c|}
\hline & $\begin{array}{l}\text { Proposed } \\
\text { system }\end{array}$ & PlyMatch & $\begin{array}{l}\text { Laser } \\
\text { projection } \\
\text { systems }\end{array}$ & $\begin{array}{l}\text { Projector } \\
\text { vision systems }\end{array}$ & $\begin{array}{l}\text { Video } \\
\text { projection } \\
\text { systems }\end{array}$ \\
\hline Accuracy & $\begin{array}{l}\text { Typical } ~ 3 \\
\text { mm, up to } 1 \\
\text { mm possible. }\end{array}$ & $\pm 1 \mathrm{~mm}$ & $\pm 0.38 \mathrm{~mm}$ & $0.38 \mathrm{~mm}$ & $2 \mathrm{~mm}$ \\
\hline Cost $^{1}$ & ZAR40,000² & $\mathrm{GB} £ 26,900^{3}$ & $\begin{array}{l}\text { US\$85,000 to } \\
\text { US\$100,000 }\end{array}$ & $\mathrm{n} / \mathrm{a}$ & $\mathrm{n} / \mathrm{a}$ \\
\hline \multicolumn{6}{|c|}{$\begin{array}{l}{ }^{1} \text { Costs estimated in October } 2014 \text {. Exchange rates at that time: } 1 \text { ZAR }=0.0901 \text { US\$; } 1 \text { ZAR }=0,0568 \\
\text { GBE. } \\
{ }^{2} \text { Cost of components } \\
{ }^{3} \text { Retail cost }\end{array}$} \\
\hline
\end{tabular}

\section{CONCLUSION}

The produced system made it possible accurately to ensure the correct placement of the prepregs and thus reduce and eliminate composite material layup errors. Using basic inexpensive components makes it an extremely competitive system, with the cost less than ZAR40,000.

The suggested lens resulted in accuracies that were unable to solve bridging. A contemporary machine vision camera is suggested to mitigate this complication. Machine vision cameras with resolutions double that of the camera used are available. Using such a camera would provide the system with approximately double the accuracy.

As the accuracy of the system decreases with an increase in the FOV of the lens used on the camera, it was found that using multiple cameras with smaller FOVs to cover the same area could make the 
system much more accurate. It would also make the system versatile in respect of the size and shape of the parts being laid up. The socket programming architecture allows for this expansion, and a feasibility study proved the concept successful. The software design could be adapted to indicate on the mould where, spatially, the prepreg placement differs from the required placement.

The main advantage of such a system, and the justification for investing in such a system, would be a reduction in defective components. Although the system does not completely eliminate human error, it does provide step-by-step quality control, and should warn the technician of layup errors. Furthermore, by recording the process steps with a camera, it provides manufacturers with better capabilities to diagnose problems and trace errors in the production of components.

\section{ACKNOWLEDGEMENTS}

Dewald Koegelenberg, Ronald Wilsenach, and Stephan Bekker are thanked for the knowledge and support they provided for the experiments. Graham Carelse is thanked for his aid in the feasibility study of the project.

\section{REFERENCES}

[1] Lukaszewicz, D.H.-J.A., Ward, C. \& Potter, K.D. 2012. The engineering aspects of automated prepreg layup: History, present and future, Compos. Part B Eng., 43(3), pp. 997-1009.

[2] Anaglyph. n.d. Anaglyph: PlyMatch ${ }^{T M}$. [Online]. Available: http://www.anaglyph.co.uk/plymatch.htm. [Accessed: 18-Oct-2015].

[3] Mason, K. 2004. Laser projection systems improve composite ply placement: CompositesWorld. [Online]. Available: http://www.compositesworld.com/articles/ laser-projection-systems-improve-composite-plyplacement. [Accessed: 18-Oct-2015].

[4] A.G.S. Inc. n.d. Assembly guidance: Automatic ply verification system. [Online]. Available: http: / /www.assemblyguide.com/apvsys. html. [Accessed: 18-Oct-2015].

[5] L.P.T. Inc. n.d. LPT100 laser projector: High speed laser radar. Laser Projection Technol. [Online]. Available: http://www.lptcorp.com/products/laser-projectors/lpt100-laser-projector/. [Accessed: 18Oct-2015].

[6] A.G.S. Inc. n.d. Laservision. [Online]. Available: http://www.assemblyguide.com/pdf/ Assembly_Guidance_LASERVISION.pdf. [Accessed: 29-Nov-2015].

[7] T.C.M. Inc. n.d. Twin Coast Metrology: Products: Projector Gage - 3D video projection. [Online]. Available: http://www.twincoastmetrology.com/projectorgage-3d-video-projection.html. [Accessed: 18Oct-2015].

[8] Andor. n.d. CCD blooming and anti-blooming: The principle of blooming. [Online]. Available: http: / /www.andor.com/learning-academy/ccd-blooming-and-anti-blooming-the-principle-of-blooming. [Accessed: 19-Nov-2015].

[9] O’Connor, P.D.T., Newton, D. \& Bromley, R. 1996. Practical reliability engineering. J. Wiley. New York. 